\title{
Premio Dr. Rodolfo Céspedes Fonseca Al mejor trabajo publicado por Acta Médica Costarricense. Enero-Diciembre 2002
}

Este año, A cta M édica Costarricense, cumplió cinco años de haber reanudado su publicación continua trimestral con al menos cuatro números al año y algunos suplementos. También han sido cinco años de distribución por correo en forma personalizada a todos los médicos inscritos en el Colegio de Médicos y Cirujanos, para los que cuentan con una dirección postal.

EI Comité Editorial de la revista se siente muy satisfecho de brindar un medio de educación médica continua a todos los médicos del país y un medio científico de alta calidad para la publicación de trabajos de investigación. Con alegría vemos que cada año ha aumentado el número de trabajos enviados para publicación, así como la participación de los lectores con los cuestionarios de autoevaluación. En este año la revista recibió 34 trabajos; se publicaron 19 trabajos originales, 9 casos clínicos, 9 revisiones bibliográficas y 29 revisiones de "Costa Rica en el exterior", así como 12 autoevaluaciones del proceso de Recertificación M édica.

A unado al gran interés de la Junta de Gobierno del Colegio de promover la investigación a nivel del cuerpo médico nacional, es que el Comité Editorial de Acta Médica Costarricense, ha querido establecer a partir de este año el premio Dr. Rodolfo Céspedes Fonseca a los 3 mejores trabajos originales publicados en la revista durante el año.

Para otorgar el premio se evaluaron todos los trabajos originales publicados mediante una serie de parámetros: estructura, contenido, referencias, beneficio al cuerpo médico, y repercusión en la Salud Pública del país. Y a cada trabajo se le asignó un puntaje para cada parámetro y se escogieron los tres con mejor puntuación. A demás se excluyeron de la evaluación todos los artículos en los cuales figuraban miembros del Comité Editorial de la revista.

El Dr. Rodolfo Céspedes fue maestro de muchas generaciones de médicos nacionales y fundó en 1957 A cta M edica
Costarricense, para promover la investigación y la publicación médica en nuestro país. El Dr. Céspedes recibe en 1945 el titulo de médico en la Universidad de Santiago de Chile y en la sesión del 10 de setiembre de 1946 es incorporado al Colegio de Médicos y Cirujanos. De 1946 a 1947 labora como médico interno en el Hospital San Juan de Dios, lugar donde obtuvo premio como el mejor médico interno del Hospital.

En ese mismo año presenta en el $X X$ Congreso $M$ édico nacional la el trabajo de investigación titulada "Enfermedad de Chagas" con el que gana "medalla de oro". Fue profesor de histología y patología general en la Facultad de Odontología y Medicina de la Universidad de Costa Rica. Fue asistente del Servicio de Anatomía Patológica del Hospital San Juan de Dios y del Hospital Central de la Caja Costarricense de Seguro Social de 1950 a 1956, luego en ambos hospitales fue ascendido a J efe de Servicio. Patólogo asesor de la Oficina Médico Forense del Ministerio de Salubridad Pública de Costa Rica de 1954 a 1964.

Los trabajos merecedores del premio Dr. Rodolfo Céspedes $F$ 2002 fueron:

Tamizaje de la retinopatía diabética tipo 2 en un área de salud del área M etropolitana, por los autores: A driana Laclé, Carlos M ora, M anuel García.

Diagnóstico directo de la mutación que causa el síndrome del cromosoma $X$ frágil, por los autores: Patricia Cuenca, Fernando M orales, Isabel Castro V.

Reconstrucción mamaria con colgajo recto abdominal: Reporte de primeros 15 casos, por el autor G ustavo Chavarría León.

Este Comité se complace en felicitar a todos los autores por sus publicaciones. 